\title{
Editorial note for upcoming special issue: Latest trends in farming.
}

\author{
Xinhua Qi \\ Institute of Agro-Environmental Protection, Chinese Academy of Agricultural Sciences, China
}

Accepted September 22, 2020

\section{Editorial Note}

Journal of Agricultural science and Botany (ISSN: 25917897) allied publication, is an international prominent journal focusing on studies pertaining to crop science, modeling of crop, organic farming, irrigation and water management, soil science, plant taxonomy, plant breeding, plant genomics, postharvest technology, agro chemicals, horticulture, land use, rural biodiversity, current agricultural practices and tools related to agriculture and botany, etc.

It is an open access and peer reviewed journal by well known Editorial Board and the compositions are peer-evaluated by potential reviewers as demonstrated by their exploration intrigue.

Journal of Agricultural science and Botany is indexed in a few indexing databases like Index Copernicus, China National Knowledge Infrastructure (CNKI), Secret Search Engine Labs, Academic Keys, SafetyLit, RefSeek, EBSCO A-Z, OCLCWorldCat, Publons, etc.

Farming is a great deal of dependent on climatic conditions and is significantly introduced to environmental change. Nevertheless, developing moreover adds to the natural change by conveying ozone hurting substances into air.

\section{Environmental change and its consequences for cultivating}

There are clear aftereffects of environmental change which are presently influencing cultivating exercises. The normal yearly and occasional precipitation has been diminishing consistently influencing all parts of cultivating in numerous districts. There is a consistent increment in heat waves, dry seasons, storms and floods across numerous countries. These regular outrageous conditions will have quick and combined impacts as the time passes.

\section{Impact of cultivating on environmental change}

Cultivating influences the fragile worldwide carbon and nitrogen pushes through sequestration and delivery from plants and soil. Cultivating additionally contributes legitimately or by implication to ozone harming substance outflows from fuel and manure creation and use, soil and waste management.

Farming contributes legitimately to the biological change by delivering two intense ozone depleting substances, methane and nitrous oxide. Methane is created by domesticated animals assimilation measures, creature compost and debased wetlands. Nitrous oxide is delivered from put away natural composts, similar to poultry excrement and inorganic substance nitrogen manures.

\section{Cultivating and environmental change mitigation}

A portion of the measures include:
- Modernizing ranches and making them vitality effective

- Better use of ranch compost and waste in biofuel and biogas creation

- Reducing the quantity of animals without influencing the milk and meat yield by developing more vitality proficient animals

- Making best utilization of accessible water by crop pivot techniques

- Adjusting the planting and reaping time to changing temperature and precipitation designs

- Developing and utilizing crop assortments more open minded to warmth, dry spell and water logging

- Advising, instructing, preparing and advising the ranchers regarding the changing situation

\section{Eco-friendly cultivating}

Climate neighborly cultivating is the most recent idea by which separated from environmental change moderation; endeavors are to be made to balance out the atmosphere and condition by cultivating.

Rural creation is basically is the way toward changing over essentially the sun based vitality into types of food vitality for utilization by people and animals.

A portion of the atmosphere amicable endeavors are:

- Taking the carbon dioxide from the air and sequestering it in plant biomass and soils,

- Reduced and effective culturing to lessen $\mathrm{CO}_{2}$ discharge into environment just as to decrease vitality consumption,

- Cover editing to diminish reliance on concoction nitrogen manures,

- Efficient nitrogen compost and excrement use for diminishing $\mathrm{N}_{2} \mathrm{O}$ emanations,

- Devising techniques and innovation to diminish, catch or keep methane discharges from creatures and excrement stockpiling,

- Decreasing the animals numbers and expanding the animals creation and effectiveness,

- Developing neighborhood markets for the produce to chop down significant distance transportation and carbon impression,

- On-Ranch vitality creation and homestead squander usage to deliver biofuels and biogas to supplant petroleum derivative, 
- Recovery and reusing of carbon, supplements and vitality from natural squanders can lessen natural toxins, reestablish environmental adjusts, moderate biodiversity and produce salary openings.

\section{Conclusion}

I wish to give some point of view from the cycling research network of Journal of Agricultural science and Botany with respect to an ongoing Editorial note of our Journal.

I exclusively accept that the quality of the journal relies upon the Eminence proximity in the Editorial Board similarly as Reviewer Board (potential reviewers) who try to make the papers productive and helpful and accommodating for established researchers.

\section{*Correspondence to:}

Xinhua Qi

Institute of Agro-Environmental Protection Chinese Academy of Agricultural Sciences

\section{China}

E-Mail: qixinhua@nankai.edu.cn 